\title{
Non-Random Distribution and Sensory Functions of Primary Cilia in Vascular Smooth Muscle Cells
}

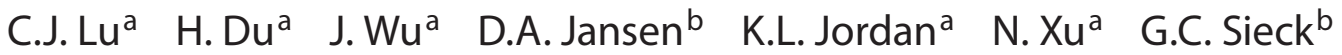 \\ Q. Qian ${ }^{a, b}$ \\ ${ }^{\mathrm{a} D i v i s i o n}$ of Nephrology and Hypertension, and ${ }^{\mathrm{b}}$ Department of Physiology and Biomedical Engineering, \\ Mayo Clinic College of Medicine and Mayo Graduate School, Rochester, Minn., USA
}

\section{Key Words}

Primary cilia Vascular smooth muscle cells .

Mechanosensing $\cdot$ Intracellular calcium $\cdot$ Integrins

\begin{abstract}
Although primary cilia are increasingly recognized to play sensory roles in several cellular systems, their role in vascular smooth muscle cells (VSMCs) has not been defined. We examined in situ position/orientation of primary cilia and ciliary proteins in VSMCs and tested the hypothesis that primary cilia of VSMCs exert sensory functions. By immunofluorescence and electron microscopic imaging, primary cilia of VSMCs were positioned with their long axis aligned at $58.3^{\circ}$ angle in relation to the cross-sectional plane of the artery, projecting into the extracellular matrix (ECM). Polycystin-1, polycystin- 2 and $\alpha 3$ - and $\beta 1$-integrins are present in cilia. In scratch wound experiments, the majority of cilia were repositioned to the cell-wound interface. Such repositioning was largely abolished by a $\beta 1$-integrin blocker. Moreover, compared to non-ciliated/deciliated cells, ciliated VSMCs showed more efficient migration in wound repair. Lastly, when directly stimulated with collagen (an ECM component and cognate ligand for $\alpha 3 \beta 1$-integrins) or induced ciliary deflection, VSMCs responded with a rise in $\left[\mathrm{Ca}^{2+}\right]_{i}$ that is depen-
\end{abstract}

dent on the presence of cilia. Taken together, primary cilia of VSMCs are preferentially oriented, possess proteins critical for cell-ECM interaction and mechanosensing and respond to ECM protein and mechanical stimulations. These observations suggest a role for primary cilia in mechanochemical sensing in vasculature.

Copyright $\odot 2008$ S. Karger AG, Basel

\section{Introduction}

Primary cilia are non-motile, hair-like projections comprised of a central axoneme organized into an annulus of 9 microtubule doublets surrounding a microtubule-free center $(9+0$ axonemal microtubule arrangement) [1]. Most mammalian cells contain single cilium emanating from the basal body located beneath the plasma membrane of the cell. The basal body contains the distal centriole, positioned adjacent to the proximal centriole and pericentriolar materials. During mitosis, primary cilia disassemble and centrioles separate, forming poles (centrosomes) supporting the astral spindles [2]. More than 450 proteins have been located to the shaft and basal body of the cilia [3-5]. Although not fully elucidated, several critical observations indicate that primary cil-

\section{KARGER}

๑ 2008 S. Karger AG, Basel

Fax +41613061234 E-Mail karger@karger.ch www.karger.com www.karger.com/kbr
Qi Qian, MD

Division of Nephrology and Hypertension, Mayo Clinic College of Medicine 200 First Street SW, Rochester, MN 55905 (USA)

Tel. +1 507266 7083, Fax +1 5072669315

E-Mail qian.qi@mayo.edu 
ia are capable of sensing extracellular signals and relaying the signals into the cell [6-10].

Defects in either structure or function of cilia are linked to a number of human diseases, collectively referred to as ciliopathies $[11,12]$. One such ciliopathy is autosomal dominant polycystic kidney disease (ADPKD), caused by mutations to the PKD1 or PKD2 gene. $P K D$ genes encode cilium-located proteins: polycystin-1 (PC1), a receptor-like protein and polycystin-2 (PC2), a member of the transient receptor protein polycystin family of calcium $\left(\mathrm{Ca}^{2+}\right)$ channel proteins [13-15]. Cilium-located polycystins in renal tubules and biliary ducts have been shown to mediate flow-induced mechanosensing $[16,17]$. The activation of such sensing triggers a transient rise in $\left[\mathrm{Ca}^{2+}\right]_{\mathrm{i}}$, which presumably evokes an array of downstream signaling responses. Primary cilia of Madin-Darby canine kidney (MDCK) cells have also been shown to respond to extracellular matrix (ECM) protein stimulation with a similar rise in $\left[\mathrm{Ca}^{2+}\right]_{\mathrm{i}}[9]$. $\mathrm{Mu}-$ tations in $\mathrm{PC} 1$ or PC2 result in ciliary sensing defects, manifested as a reduction in tubular fluid-flow-mediated $\mathrm{Ca}^{2+}$ influx and ensuing $\left[\mathrm{Ca}^{2+}\right]_{\mathrm{i}}$ rise. In biliary epithelial cells, reduction in ciliary $\mathrm{Ca}^{2+}$ influx is further associated with an inadequate inhibition to adenylyl cyclase 6 (a known $\mathrm{AC}$ isoform negatively regulated by $\mathrm{Ca}^{2+}$ ), leading to cellular cAMP accumulation $[7,16,17]$.

ADPKD is associated with prominent vascular abnormalities, including abnormal arterial wall thickening, spastic vasocontraction, intracranial aneurysm formation and rupture, and dissecting thoracic aneurysms [1821]. The pathogenesis of these vascular manifestations, to date, has not been elucidated. We previously demonstrated that the arterial wall in $P k d 2^{+/-}$mice (orthologous ADPKD model) exhibits an irregular thickness [22]. $P k d 2^{+/-}$vascular smooth muscle cells (VSMCs) show reduction in the basal $\left[\mathrm{Ca}^{2+}\right]_{i}$ as well as an agonist-induced $\left[\mathrm{Ca}^{2+}\right]_{\mathrm{i}}$ rise $[22,23]$. Additionally, possibly downstream to the $\left[\mathrm{Ca}^{2+}\right]_{\mathrm{i}}$ reduction, cellular cAMP content in $\mathrm{Pkd2}^{+/-}$ VSMCs is elevated $[22,24]$. These observations raise the possibility of a functional role for cilia of VSMCs and ciliary polycystins in vasculature. However, since the initial description of primary cilia over a century ago [25], only one report by Poole et al. [26] describes the presence of primary cilia in cultured VSMCs.

In the present study, we characterized the spatial distribution and orientation of primary cilia in the aortic media and in primary cultured VSMCs after induced wounding, and examined the presence of cilium-associated proteins that are known to exert mechanosensing and cell-ECM interaction. Furthermore, we tested the hypothesis that (1) primary cilia redistribute and play a role in wound repair by examining the healing process of VSMCs after scratch wounding, and (2) primary cilia exert mechanochemical sensing function by examining cilium-mediated $\left[\mathrm{Ca}^{2+}\right]_{\mathrm{i}}$ response to type 1 collagen stimulation and ciliary deflection.

\section{Materials and Methods}

Isolation of VSMCs and Chloral Hydrate Deciliation

Dissociation of VSMCs from the thoracic aortas of adult C57/ BL6 mice (age 12-15 weeks) was carried out as described previously [22]. Ciliated VSMCs were treated with $4 \mathrm{mM}$ chloral hydrate in DMEM as described [27]. Medium containing chloral hydrate was changed twice daily.

Cryosections, Immunofluorescence and Confocal Microscopy Intact thoracic arteries, oriented on tragacanth gum paste $\left(1 \mathrm{~g} / 10 \mathrm{ml} \mathrm{H} \mathrm{H}_{2} \mathrm{O}\right)$ initially, were flash frozen in isopentine, followed by embedding in OCT compound (Tissue-Tek) and frozen in liquid nitrogen. 5- or 10- $\mu \mathrm{m}$ cryosections, perpendicular and longitudinal in relation to the long axis of the arteries, were fixed in 2:1 methanol:acetone, permeabilized in $0.5 \%$ Triton-X 100 overnight, quenched in $20 \mu \mathrm{M}$ glycine, and blocked in 9:1 TBST:goat serum. The sections were then incubated with appropriate primary antibodies, followed by PBS rinsing and incubation in secondary antibodies conjugated to Texas Red or Alexa Fluor 488. Images were obtained using a Zeiss LSM 510 confocal laser scanning microscope (Carl Zeiss Inc., Thornwood, N.Y., USA) with $40 \times$ and $63 \times$ water immersion lenses and/or a $100 \times$ Plan-Apochromat 1.4 oil objective lens.

\section{Scanning and Transmission Electron Microscopy}

The dissected aortas were immersed in $2 \%$ phosphate-buffered glutaraldehyde on ice $(\times 1 \mathrm{~h})$, rinsed in PBS, and postfixed in $1 \%$ osmium tetroxide $(\times 1 \mathrm{~h})$. After being rinsed in distilled water, the samples were dehydrated in serial ethanol. For scanning electron microscopy, the samples were dried in a critical point dryer, sputter-coated with gold-palladium, sectioned and examined using a Hitachi 4700 scanning electron microscope. For transmission electron microscopy, the samples were infiltrated/embedded with Spurr's resin, sectioned and examined using a Jeol 1200 transmission electron microscope.

Scratch Wounding and Wound Filling

Confluently cultured and growth-arrested VSMCs (passage $3-7)$ were scratched linearly using a $20-\mu l$ sterile pipette tip. After washing off the detached cells and debris, DMEM with 1.0\% FBS was added, several wounded areas were marked for orientation, and serial phase contrast pictures were taken at the marked areas at multiple time points. The percentage wound filling was quantified using a MetaMorph software program (Version 6.3r5, Molecular Devices, Downingtown, Pa., USA). The unfilled wound area at each time point $(9,12$ and $24 \mathrm{~h}$ ) was outlined manually; the software program generated a number for each outlined area. The percentage of wound filling was derived from subtracting the measured area from the corresponding area before wounding. 
Global $\left[\mathrm{Ca}^{2+}\right]_{i}$ Measurements by Fura-2 and Recording

Techniques

Monolayer of confluently cultured and growth-arrested VSMCs grown on coverslips was loaded with $5 \mu \mathrm{M}$ Fura-2AM ( $\times 30 \mathrm{~min}$ ), rinsed in HBSS and mounted in an open flow chamber on the stage of an inverted Nikon Diaphot microscope. Laminar flow rates were adjusted to 1.0 or $3.5 \mathrm{ml} \mathrm{min}^{-1}$ as needed. The cells were equilibrated in $\mathrm{HBSS}$ at $1.0 \mathrm{ml} \mathrm{min}^{-1}$ flow $\left(37^{\circ} \mathrm{C}\right.$ and aerated with a mixture of $95 \% \mathrm{O}_{2}$ and $5 \% \mathrm{CO}_{2}$ ) for 45 min before each experiment. The recoding of R340/380, as an indicator of intracellular free $\mathrm{Ca}^{2+}$, was as detailed in our previous studies [24]. The viability of VSMCs was ascertained by the observation of a brisk $\left[\mathrm{Ca}^{2+}\right]_{\mathrm{i}}$ response to $100 \mathrm{mM} \mathrm{KCl}$ stimulation at the end of each experiment. Data were analyzed using a MetaFluor v.7130.

\section{Reagents and Antibodies}

Unless otherwise specified, all reagents were obtained from Sigma. Antibodies were purchased from Santa Cruz, Calif., USA (PC1, PC2, $\alpha 3$-integrin, centrin-1/2 antibodies), Abcam, Mass., USA ( $\beta 1$-integrin antibody), Sigma, Mo., USA (anti-acetylated $\alpha$-tubulin, anti- $\gamma$-tubulin antibodies). Fura-2AM was obtained from Molecular Probes, Oreg., USA, and soluble rat tail type 1 collagen from BD Biosciences, Calif., USA.

\section{Statistical Analysis}

Data are expressed as mean \pm SEM. Student's t test and twoway ANOVA with Bonferroni's post-hoc analysis were used for comparisons between different groups. A p value of $<0.05$ was considered significant.

\section{Results}

\section{Primary Cilia of VSMCs in the Aortic Media Are}

Preferentially Oriented and Exhibit Varying Degrees

of Deflection

Primary cilia of VSMCs in cross-sectional and longitudinal sections of the descending thoracic aortas were examined by immunostaining using a monoclonal antibody against acetylated $\alpha$-tubulin. Acetylated $\alpha$-tubulin is found to be highly concentrated in the ciliary axoneme [28]. In accordance with reported observations [26, 28], we found the antibody was concentrated in discrete regions of the cells consistent with primary cilia. The remainder of the cytoplasm was faintly stained. No ciliumlike structure in parallel staining was detected when the primary antibody was replaced by preimmune serum, confirming the specificity of the antibody in VSMCs.

A large number of sections prepared from three wildtype aortas were examined. We were able to identify, in most of VSMCs, single cilium per cell (fig. 1B). Because cilia in intact tunica media locate throughout the thickness of a given section (5 or $10 \mu \mathrm{m}$ ), we stacked multiple $(\geq 20)$ individual confocal images $(63 \times$ water immersion lens) to demonstrate the single cilia of VSMCs. As a draw- back of such stacking, the detailed presentation of primary cilia in the stacked image was not nearly as clear as a single confocal image or stacked with 2-3 consecutive images using $100 \times$ oil lens, as depicted in figure $2 \mathrm{~A}$ and C. Nevertheless, figure $1 \mathrm{~B}$ unequivocally demonstrates the distribution of primary cilia in situ.

Three-dimensional (3D) reconstructions of serial confocal images and scanning and transmission electron microscopy added insights to their in situ orientation. We found that primary cilia were not randomly oriented. They projected from VSMCs into the adjacent ECM (fig. 2A-E) with an average length of cilia consistently being at their maximum when $3 \mathrm{D}$ reconstructions of the cross-sectional confocal images were rotated to $58.3^{\circ}$ (fig. 1C), indicating that the overall long axis of primary cilia were aligned at an approximately $60^{\circ}$ angle in relation to the cross-sectional plane of the artery. The potential aberration in 3D reconstructions associated with refractory index mismatch, which might slightly overestimate cilium lengths at $90^{\circ}$ rotation, is expected to be insignificant here because we had kept the numeric aperture at $<1.2$ and the sample thickness $\leq 10 \mu \mathrm{m}[29,30]$.

It should be noted that the numeric numbers of cilium length measured from the 3D-reconstructed images, as shown in figure $1 \mathrm{D}$, almost certainly underestimate their true length because the majority of cilia exhibited varying degrees of deflection (fig. 2A-E). 78 of the 86 (92\%) cilia, observed under $100 \times$ oil lens, showed deflection, which would render the measured ciliary lengths under the lower magnification less than the actual ones. Based on the SEM/TEM images (fig. 2D, E), the cilium length of VSMCs in situ was estimated to be approximately $3-5 \mu \mathrm{m}$.

\section{Primary Cilia of VSMCs Express Polycystins and $\alpha 3-$ and $\beta 1$-Integrins}

In epithelial cells and chondrocytes, ciliary membrane possesses an array of membrane proteins, including PC1, PC2, and integrins [9, 31, 32]. Whether or not they are present in cilia of VSMCs is unknown. As shown in figure 3A (upper panel), in intact aortic media, PC1 and PC2 were colocalized with acetylated $\alpha$-tubulin. Two sets of antibodies for PC1 (Santa Cruz, sc 25570 and 7e12 [33]) and PC2 (Santa Cruz, sc 25749 and P30 [22]) were separately used for the detection of polycystins; both generated identical results. To confirm that the observed colocalization did not result from spurious interaction between the primary antibodies to PC1 or PC2 and acetylated $\alpha$-tubulin, we separately stained VSMCs with PC1 or PC2 antibody and co-stained them with antibody to $\gamma$-tubulin. As shown in figure 3A (lower panel), $\mathrm{PC1}$ or 

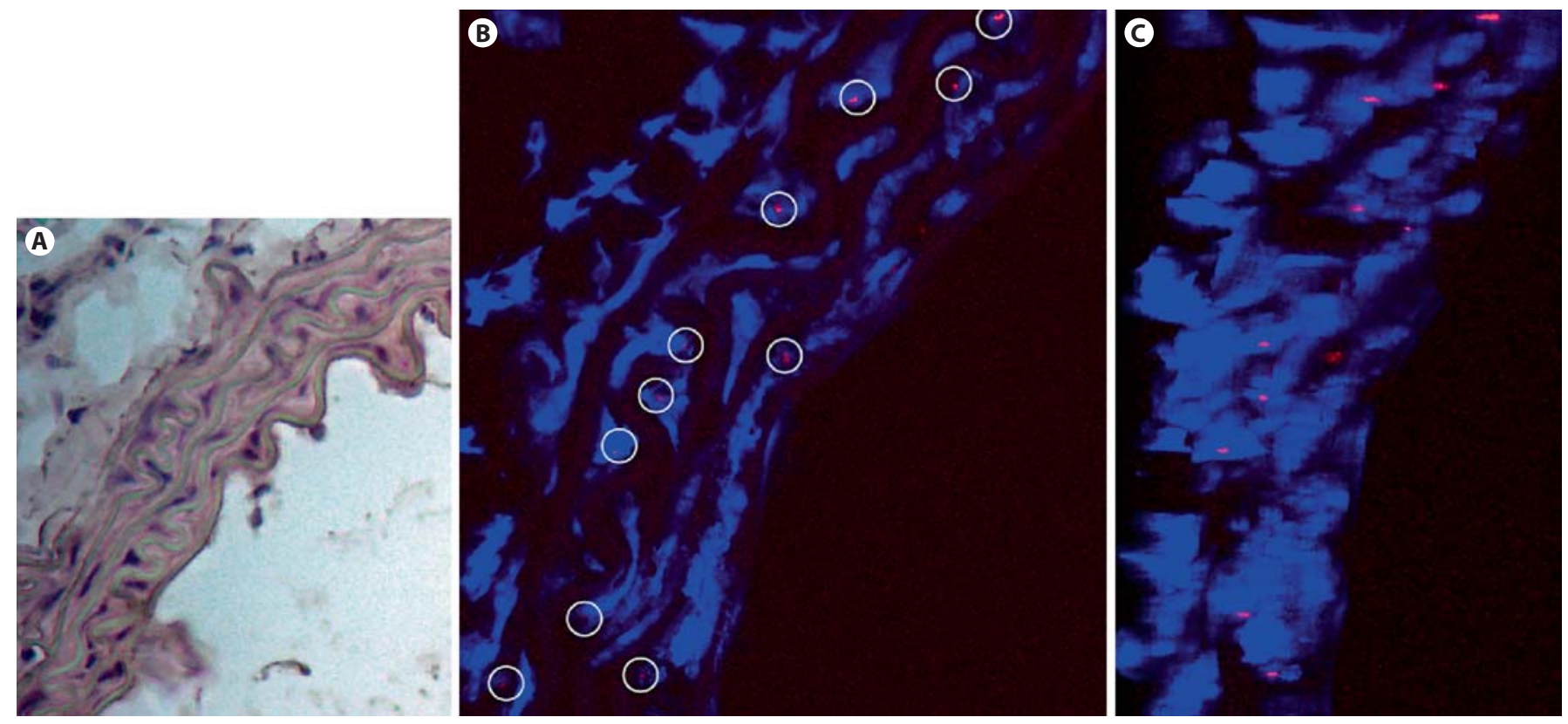

Fig. 1. A HE staining of a cryosection, showing VSMCs within rings of aortic lamellae. B A cryosection consecutive to the section in A was immunostained with primary cilia marker, acetylated $\alpha$-tubulin and the secondary antibody conjugated to Texas-Red. Twenty-two consecutive confocal images, taken under a $63 \times$ water immersion lens, were stacked to show the presence of primary cilia (in circles) in the majority of VSMCs in the tunica media. DAPI stained for the nuclei of VSMCs. C Primary cilia project with their long axis aligned at an approximately $60^{\circ}$ in relation to the cross-sectional plain of the artery. D Lengths of primary cilia measured at varying angles in relation to the cross-sectional plane of the arteries. Data are collected from $>3$ separate sets of immunostainings of primary cilia.

PC2 antibody localized to the expected position of the cilia, while $\gamma$-tubulin antibody was concentrated at the basal body, further confirming the presence of PC1 and PC2 in primary cilia of VSMCs.

Given our observation that VSMC cilia in situ projected into the dense ECM lamellae, we sought evidence for interaction between the cilia and ECM proteins. Integrins are heterodimeric receptors for ECM proteins; when ligated, they not only link ECM to the intracellular cytoskeleton but also activate multiple signaling molecules $[34,35]$. As depicted in figure 3B, we found, by immunocolabeling, that $\alpha 3$ - and $\beta 1$-integrins (at a 1:500 dilution for each primary antibody) were clearly present in the shaft of primary cilia, in a punctate manner. These specific integrins were chosen because they are known to be critically involved in VSMC-ECM interaction, are indispensable $[36,37]$ and are expressed in a similar abundance in freshly dissociated and primary cultured VSMCs [38].

\section{Primary Cilia of VSMCs Are Aligned at the Interface between VSMCs and the Induced Wound}

Alignment of primary cilia in the direction of cell migration was described in 3T3 cells and rat 3YI cells [3941], suggesting a role for cilia in directional cell migration. To determine whether this phenomenon occurs in VSMCs, confluently cultured VSMCs were scratch-wounded. 3.5$5.5 \mathrm{~h}$ after wounding, the cells were fixed and primary cilia labeled with anti-acetylated $\alpha$-tubulin. The presence of cilia in these cells was also verified by SEM (fig. 4A, inset). As shown in figure $4 \mathrm{~A}-\mathrm{C}$, while no specific pattern 

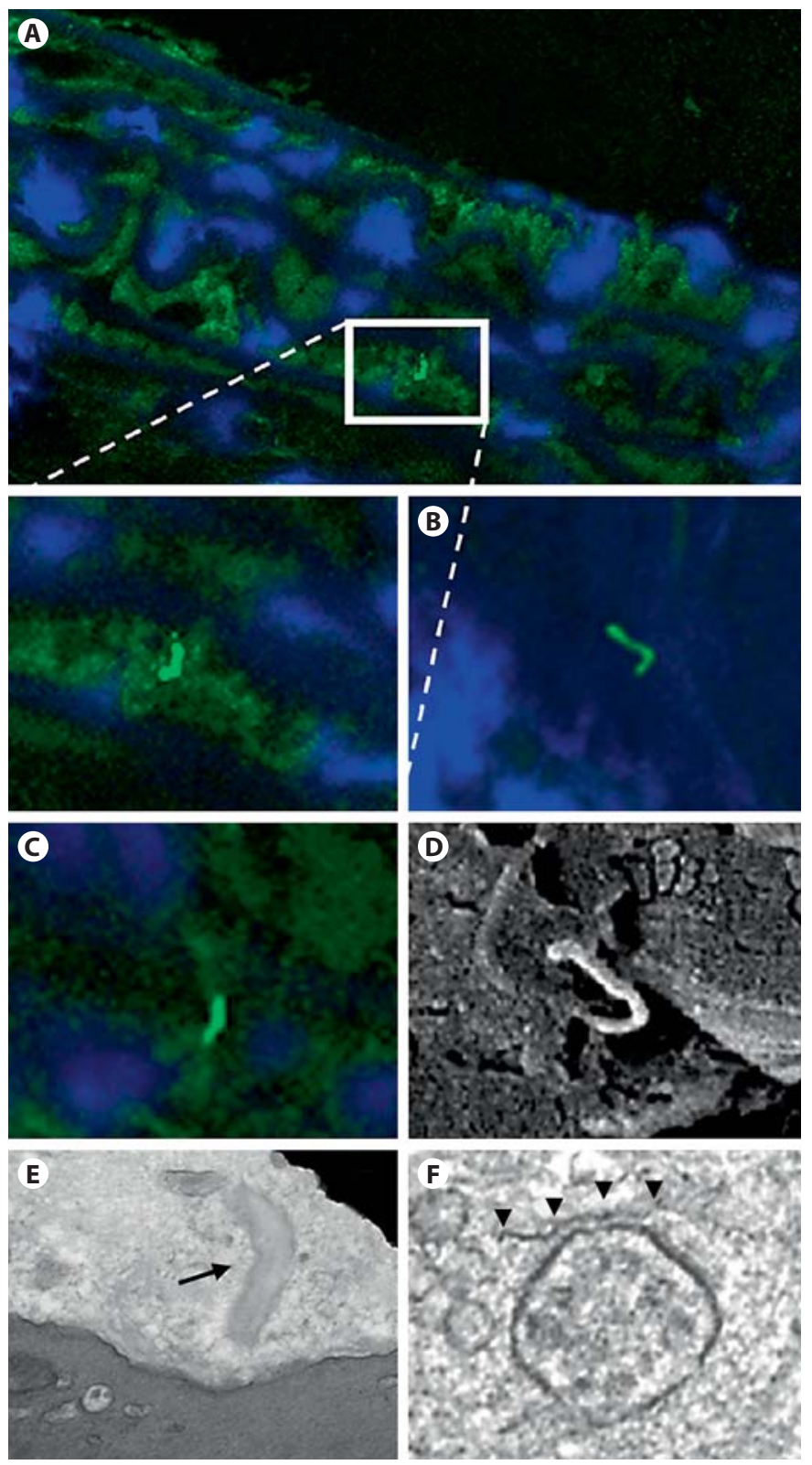

Fig. 2. Primary cilia in the aortic media project into the adjacent ECM. Three representative immunostaining images, taken by $100 \times$ oil immersion lens (A-C), show varying degrees of bending in the shaft of each cilium. Two consecutive confocal images were stacked at times to show the entire cilia. DAPI stained for the nuclei of VSMCs. D shows a SEM image of a primary cilium at a cross section of the aortic media. $\mathbf{E}$ shows a TEM image of a ciliary axoneme within the aortic media extending into the surrounding ECM with angulation. Arrow indicates the bending. $\mathbf{F}$ shows a TEM image of a primary cilium at the cross section of an intact aortic media. It locates nearby the cell surface and, notably, shows the absence of the central doublet microtubules, a hallmark of $9+0$ microtubule arrangement of primary cilia. Arrowheads indicate the plasma membrane.

Primary Cilia in Vascular Smooth Muscle Cells of distribution could be found in non-wounding areas, the distribution of primary cilia in VSMCs at the wound edge was highly patterned. A majority aligned at the outer edge of the wound in front of the nuclei, interfacing between the cells and wound. Of the 172 cilia observed at the wound edges in four separate experiences, 152 (88.3\%) were positioned at the interface. Frequently, these leadingedge cilia had their long axis pointing towards the wound/ open space in front of them (fig. 4B, C). The redistribution implies that primary cilia of VSMCs might play a role in cell migration and wound healing.

\section{Alignment of Primary Cilia after Wounding Is Mediated by Integrins}

ECM proteins, after injury, expose their matricryptic sites that are highly interactive with their receptor, integrins $[42,43]$. The scratch wounding is expected to expose these sites and enhance ECM-integrin cross-linking. To determine whether the ciliary alignment at the outer edge of the wounding was mediated via the interaction of ciliary integrins and ECM proteins, we repeated the wounding experiments after the cells were pretreated with a $\beta 1$-integrin function-blocking antibody. As shown in figure $4 \mathrm{D}$, the ciliary relocation was markedly reduced after $\beta 1$-integrin blockage. Only 29.3\% (34 of 116) VSMCs were found to have their cilia positioned at the leading edge $(\mathrm{p}<0.01)$ compared to those without integrin blockage. These findings indicate that the ciliary redistribution after wounding is, at least in part, mediated via ciliary integrin-ECM interaction.

\section{Deciliated VSMCs Exhibit a Delay in Wound Filling}

The relocation of primary cilia after induced wounding raises the question of whether primary cilia play a role in assisting/directing VSMC migration. To directly examine this possibility, we performed the same wounding experiments in VSMCs either non-ciliated (not growtharrested by serum starvation) or deciliated by treating the ciliated cells with chloral hydrate $(4 \mathrm{mM})$ [8]. Chloral hydrate dissolves the transitional fibers at the plasma-membrane-anchoring region of primary cilia. This deciliation method has been routinely used to assess the ciliary mechanosensory functions and shown to be non-toxic to cells and without significant alterations in cytoskeleton systems $[7,8,27,44]$. As shown in figure $5 \mathrm{~A}$ and $\mathrm{B}$, compared to ciliated VSMCs, non-ciliated and deciliated VSMCs showed a retarded wound filling, indicating a ciliary contribution to the optimal VSMC migration after injury. The migrational pattern was indistinguishable between non-ciliated and deciliated VSMCs. 

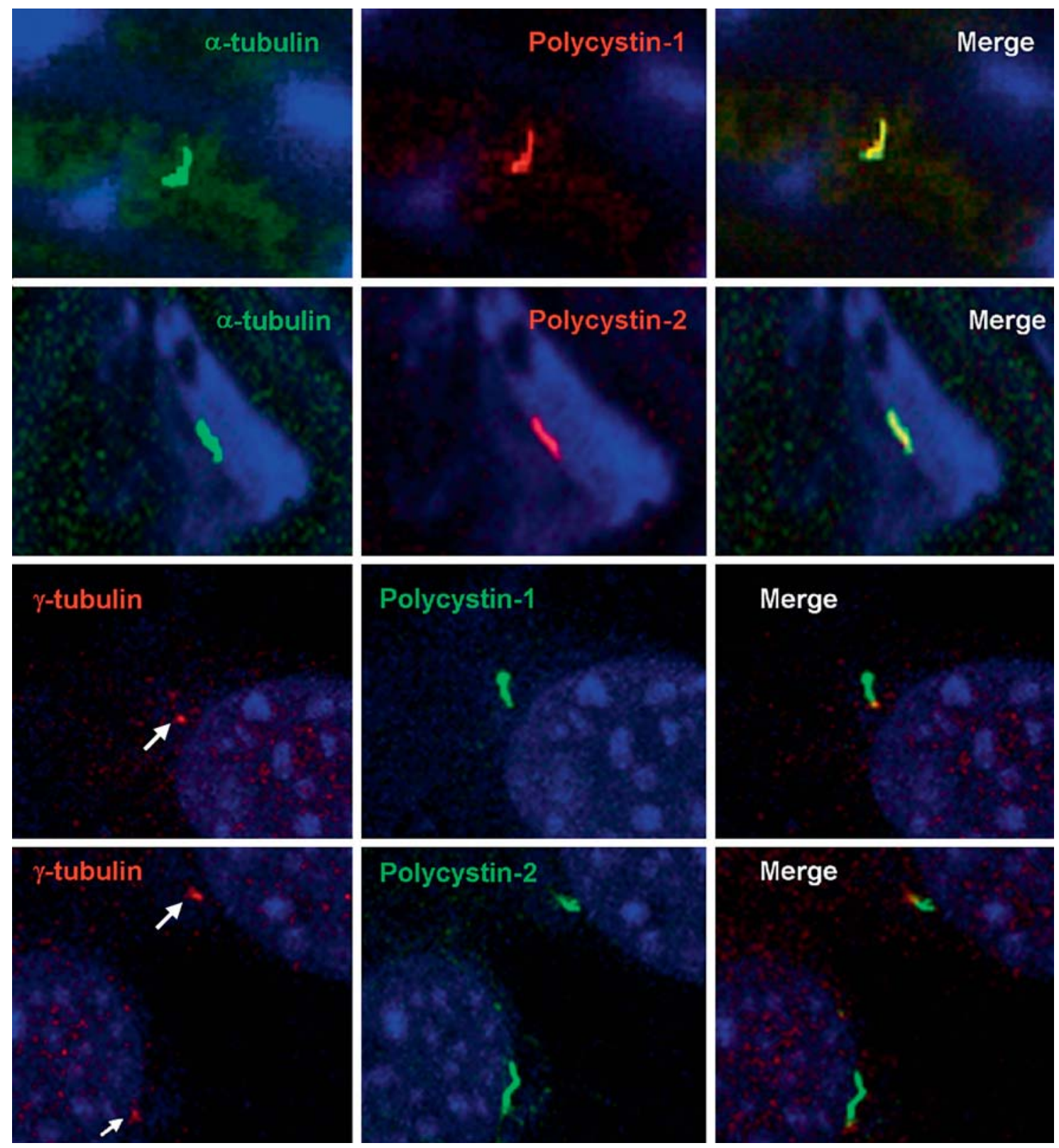

Fig. 3. A Upper panels: co-labeling of primary cilia with acetylated $\alpha$-tubulin (Alexa Fluor 488) and PC1 (Texas red) or PC2 (Texas red) in the aortic media. Lower panels: co-labeling of basal body with $\gamma$-tubulin (Texas red) and PC1 (Alexa Fluor 488) or PC2 (Alexa Fluor 488) in primary cultured VSMCs, showing the presence of polycystins in primary cilia. DAPI stained for the nuclei of VSMCs. Arrows indicate basal bodies.

Primary Cilia of VSMCs Augment Collagen-Induced $\left[\mathrm{Ca}^{2+}\right]_{i}$ Response

Interactions of VSMCs with ECM proteins play a crucial role in tissue homeostasis $[45,46]$. To determine the functional significance of ciliary $\alpha 3$ - and $\beta 1$-integrins, we directly examined the response of ciliated VSMCs to type 1 collagen stimulation (containing collagen frag- ments). Type 1 collagen is one of the cognate ligands of $\alpha 3 \beta 1$-intergrins. As shown in figure 6A (first bar) and C, collagen, introduced at a minimum flow rate $(1.0 \mathrm{ml}$ $\left.\mathrm{min}^{-1}\right)$, elicited a rise in the $\left[\mathrm{Ca}^{2+}\right]_{\mathrm{i}}$ in ciliated VSMCs. The same response was also elicited by gently adding collagen containing solution to the chamber using a pipette without minimal flow. As shown in figure $6 \mathrm{~B}$, the $\left[\mathrm{Ca}^{2+}\right]_{\mathrm{i}}$ re- 

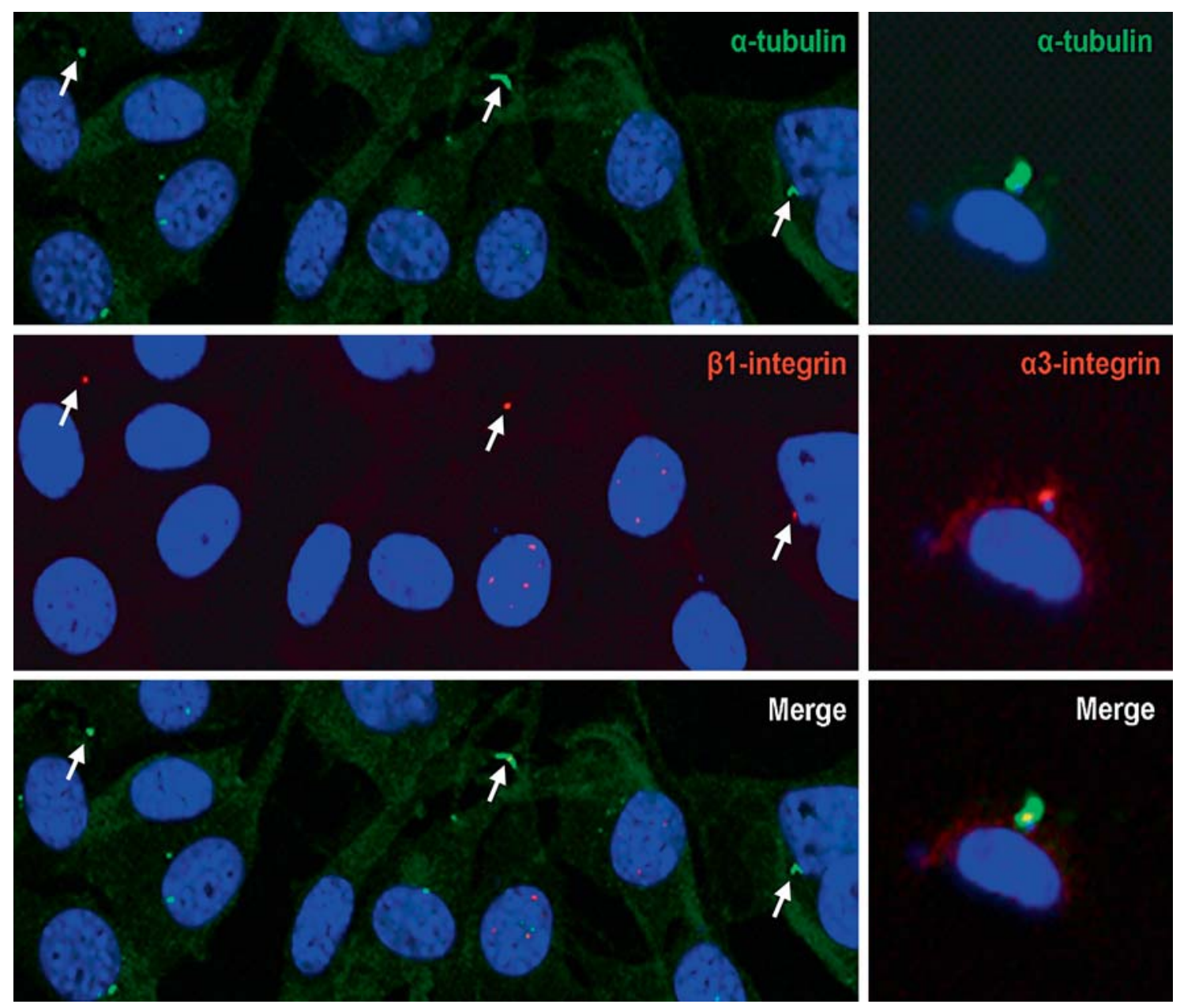

Fig. 3. B Co-labeling of primary cilia with acetylated $\alpha$-tubulin (Alexa Fluor 488 ) and $\beta 1$ - and $\alpha 3$-integrins (Texas red), showing punctate colocalization. DAPI stained for the nuclei of VSMCs. Arrows indicate labeled primary cilia and $\beta 1$-integrin.

sponse to collagen stimulation appeared to be dose-dependent. To ascertain whether or not the $\left[\mathrm{Ca}^{2+}\right]_{\mathrm{i}}$ response was integrin-mediated, we pretreated the cells with a function-blocking anti- $\beta 1$-integrin antibody $(0.16 \mu \mathrm{g} /$ $\mathrm{ml}$ ) for $30 \mathrm{~min}$. As shown in figure 6A (third bar), the $\left[\mathrm{Ca}^{2+}\right]_{\mathrm{i}}$ response was almost completely blocked, consistent with a specific $\beta 1$-integrin-mediated response. To further confirm that ciliary integrin contributed to the integrin-activation-mediated $\left[\mathrm{Ca}^{2+}\right]_{\mathrm{i}}$ rise, we repeated the same experiments using VSMCs that were either nonciliated or deciliated by chloral hydrate. As shown in figure $6 \mathrm{~A}$ (second bar), $\mathrm{B}$, and $\mathrm{D}$, without primary cilia, the $\left[\mathrm{Ca}^{2+}\right]_{\mathrm{i}}$ responses to the same stimulation were markedly blunted. These results indicate that cilium-located integrins can be activated by ECM component and transduce signals intracellularly.

Primary Cilia in Vascular Smooth Muscle Cells

\section{Ciliary Deflection in VSMCs Potentiates $\left[\mathrm{Ca}^{2+}\right]_{i}$}

Response

Bending of primary cilia in epithelial cells initiates mechanosensing. The observation of ciliary deflection in situ and the presence of polycystins in cilia imply a mechanosensing function of cilia in VSMCs. To test this possibility, we deflected cilia to reproduce in vivo ciliary conformation and examined the attendant response in the $\left[\mathrm{Ca}^{2+}\right]_{i}$. Primary cilia could be deflected either by direct manipulation using a micropipette or by applying force onto the shaft of cilia by fluid flow. Both methods show a nearly identical result $[8,47]$. We elect to deflect cilia using fluid-flow-induced drag force because this method is not only relatively easy to apply, but also allowing us to monitor the $\left[\mathrm{Ca}^{2+}\right]_{\mathrm{i}}$ response in multiple cells simultaneously. A monolayer of primary cultured VSMCs

Kidney Blood Press Res 2008;31:171-184 177 

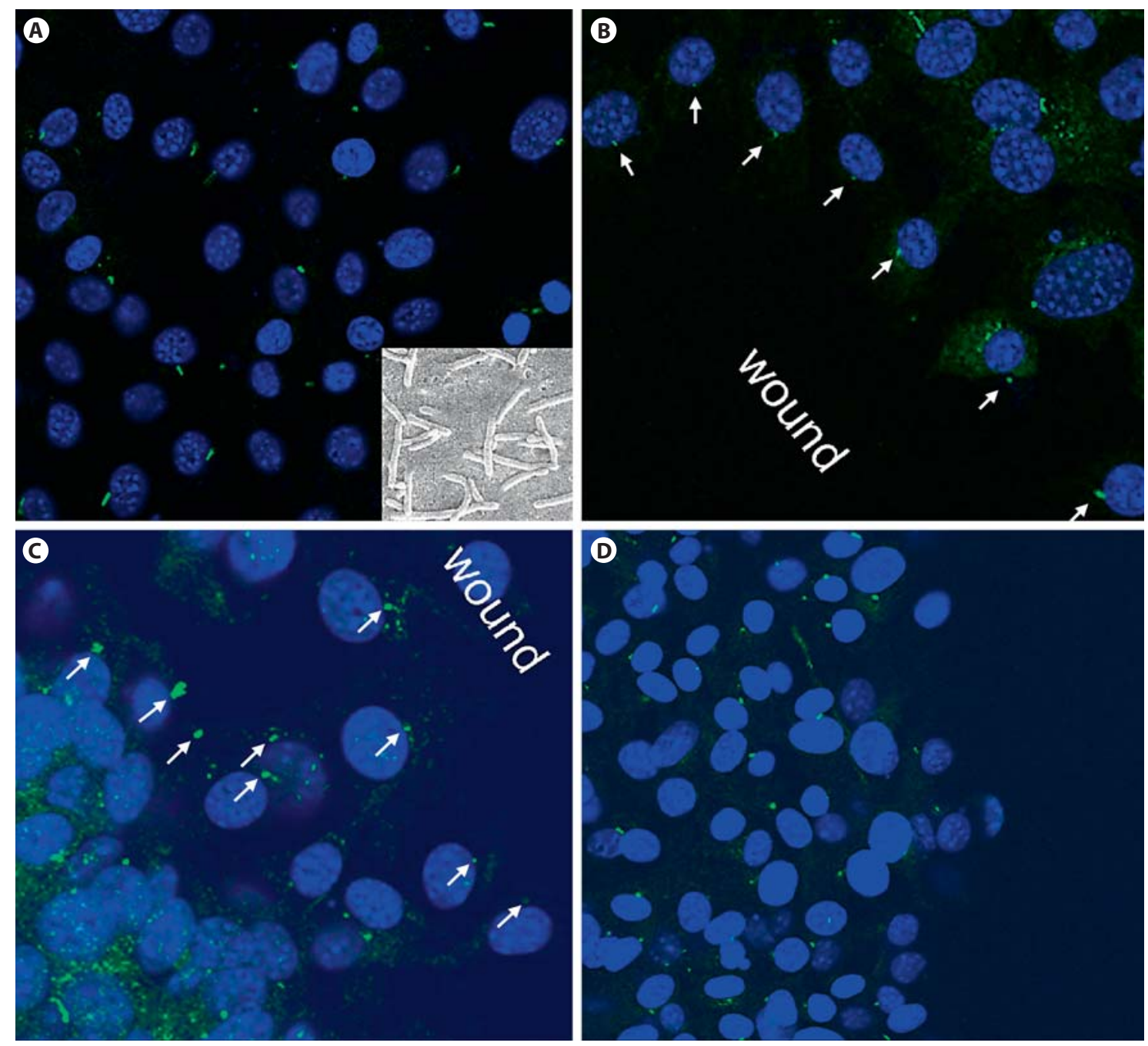

Fig. 4. Primary cultured VSMCs before (A) and $3.5 \mathrm{~h}(\mathbf{B})$ and $5.5 \mathrm{~h}(\mathbf{C})$ after scratch wounding, showing primary cilia, immunostained with acetylated $\alpha$-tubulin antibody conjugated to Alexa Fluor 488, were positioned towards the direction of the wounding (arrows indicate primary cilia) and ahead of the nuclei. DAPI stained for the nuclei of VSMCs. The inset in $\mathbf{A}$ shows a SEM image of primary cilia in these VSMCs. D shows a representative image of VSMCs, treated with $\beta 1$-integrin blocker, immunostained with acetylated $\alpha$-tubulin antibody conjugated to Alexa Fluor 488 at $5.5 \mathrm{~h}$ after scratch wounding. $\mathbf{A}$ and $\mathbf{D}$ are confocal images taken with $40 \times$ water immersion lens. B was taken with $63.3 \times$ water immersion lens and $\mathbf{C}$ was taken with $100 \times$ oil lens. (passaged $\leq 5$ ) was subjected to a laminar fluid flow at a rate of $3.5 \mathrm{ml} \mathrm{min}{ }^{-1}$, which is predicted to produce a drag force on the shaft of cilia of approximately $1 . \mathrm{E}+01 \mathrm{pN} / \mu \mathrm{m}$ [44]. As shown in figure 7A and B, ciliated VSMCs responded to the deflection with a transient increased $\left[\mathrm{Ca}^{2+}\right]_{i}$. Although the magnitude of $\left[\mathrm{Ca}^{2+}\right]_{\mathrm{i}}$ responses vary, possibly related to an uneven degree of force-induced ciliary deflection, the vast majority of VSMCs $(>95 \%)$ exhibited a response. To further ascertain that the $\left[\mathrm{Ca}^{2+}\right]_{\mathrm{i}}$ response is cilium-mediated, the same experi- ments were repeated using VSMCs deciliated with chloral hydrate. As shown in figure 7A (second bar) and $\mathrm{C}$, the deciliation blunted the $\left[\mathrm{Ca}^{2+}\right]_{\mathrm{i}}$ rise in response to the same mechanical stimulation. Similar results were also noted in non-growth-arrested, thus non-ciliated VSMCs (fig. 7A, third bar). These results demonstrate the deflection of cilia in VSMCs triggers a $\left[\mathrm{Ca}^{2+}\right]_{i}$ rise. 
Fig. 5. A Percentage wound fillings (mean \pm SEM) in ciliated (clear bars), non-ciliated (gray bars), and deciliated (black bars) VSMCs at 9,12 , and $24 \mathrm{~h}$ after scratch wound $(\mathrm{n}=3)$. Results between ciliated and non-ciliated or deciliated groups were compared using two-way ANOVA with Bonferroni's post-hoc analysis. Ciliated VSMCs showed a faster wound filling than that of non-ciliated or deciliated VSMCs $(\mathrm{p}<0.001) .{ }^{*}$ Denotes a significant difference. B Representative phase-contrast images showing VSMC migration and wound filling at $0,9,12$, and $24 \mathrm{~h}$ after scratch wounding in ciliated (top panel) and deciliated (bottom panel) VSMCs.

B
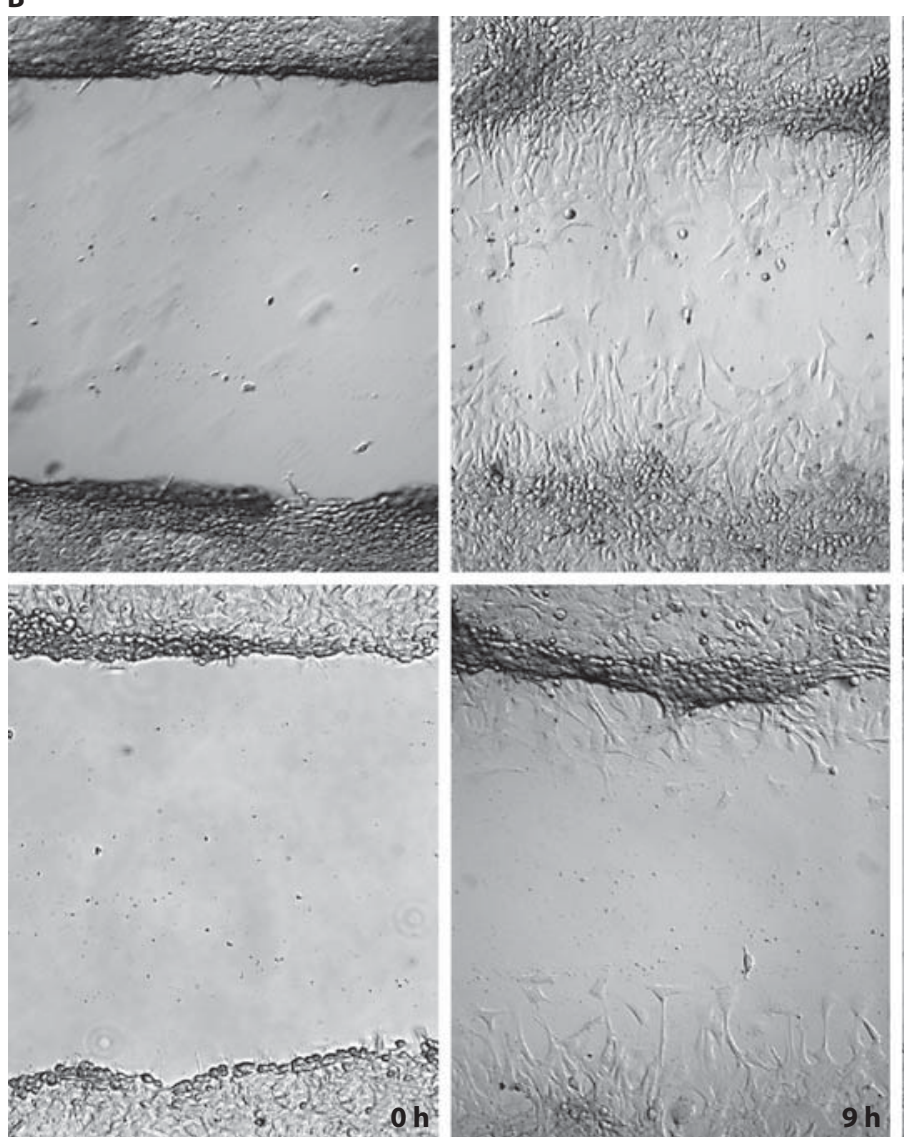

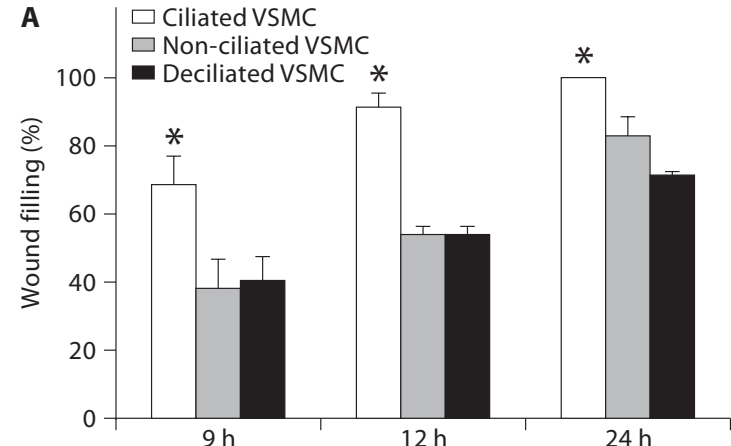

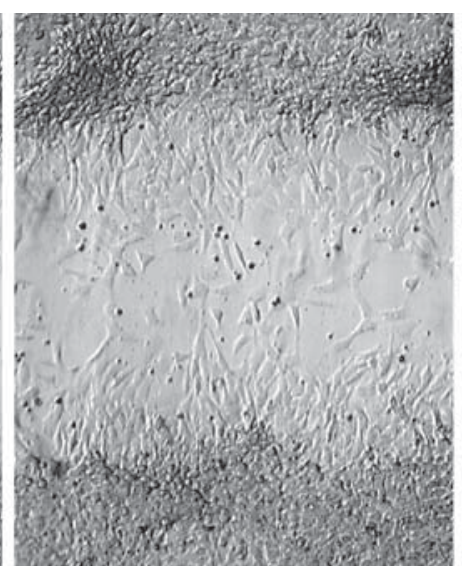
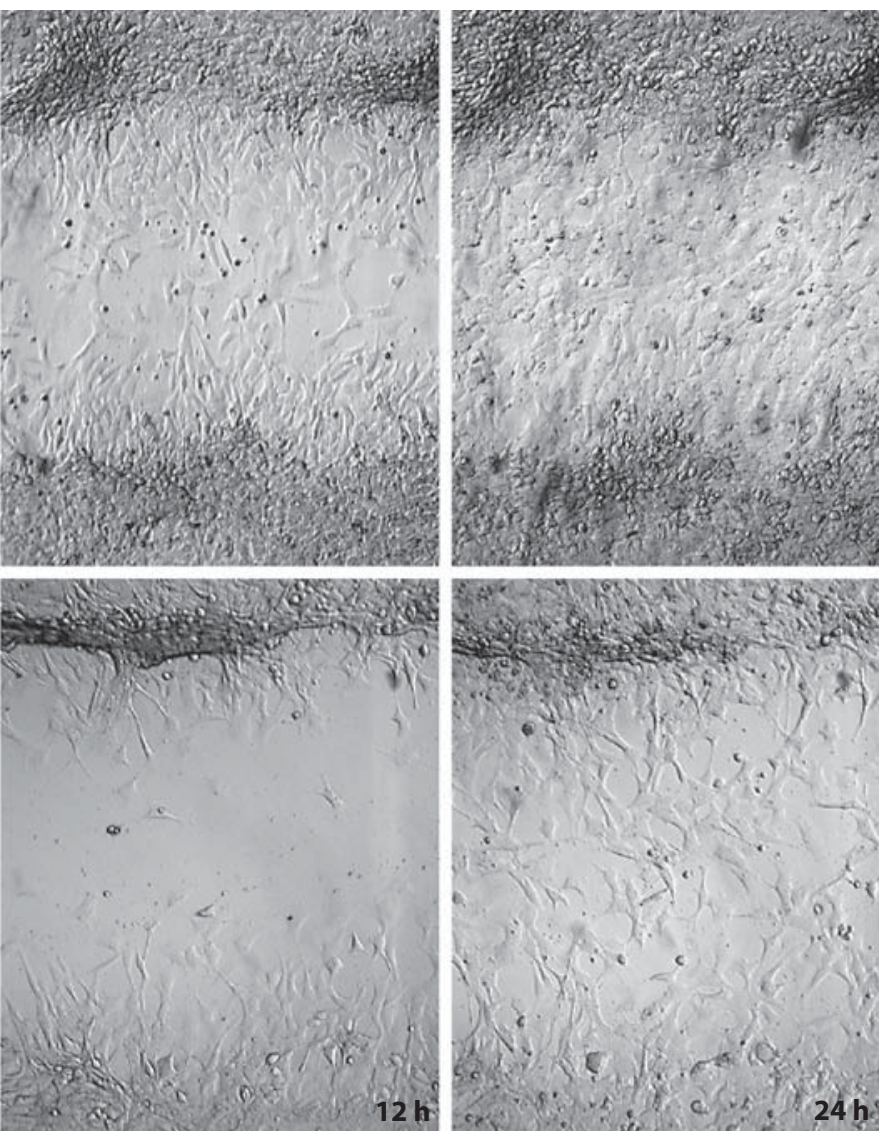

\section{Discussion}

This study provides the first detailed examination of primary cilia in VSMCs in the intact artery, including their position/orientation, axonemal ultrastructure under electron microscopy and associated proteins. Func- tional examinations demonstrated that primary cilia of VSMCs mediate ECM-protein sensing and fluid-flow-induced mechanosensing.

Mechanical perturbations are constantly imposed on intact arteries from a variety of sources: turbulence of blood flow, stretching of the vessel wall, and contraction 


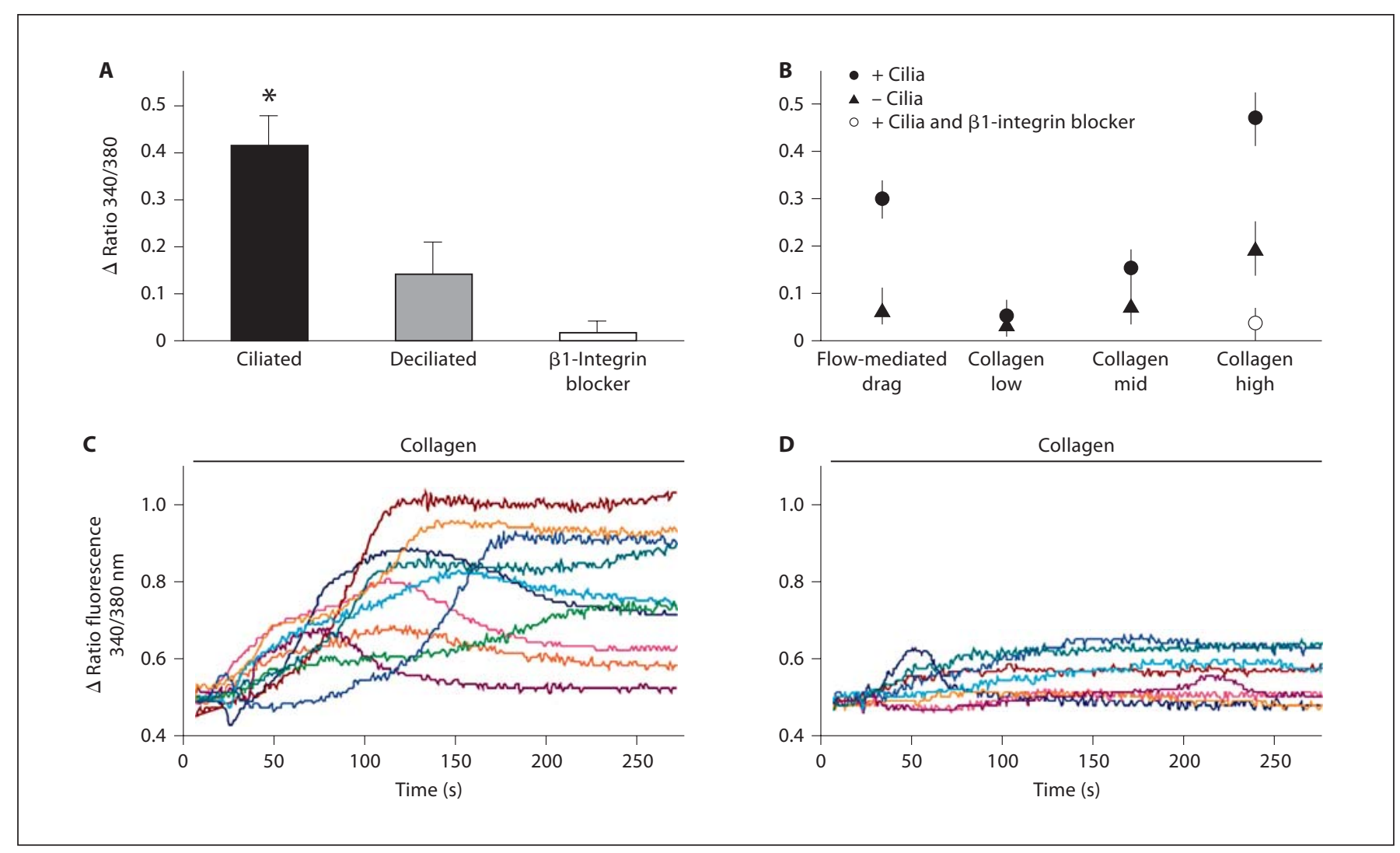

Fig. 6. A $\left[\mathrm{Ca}^{2+}\right]_{\mathrm{i}}$ responses, represented by the changes in ratio of $340 / 380$, to the addition of type 1 collagen in ciliated $0.422 \pm 0.076(\mathrm{n}=46)$, deciliated $0.148 \pm 0.038(\mathrm{n}=40)$, and ciliated but $\beta 1$-integrin blocker treated $0.018 \pm 0.011(\mathrm{n}=42)$ VSMCs, with 3 separate sets of experiments for each cell group $(\mathrm{p}<0.001) .{ }^{*}$ Denotes a significant difference comparing ciliated to deciliated VSMCs, and to ciliated VSMCs pretreated with $\beta 1$-integrin blocker. $\mathbf{B}\left[\mathrm{Ca}^{2+}\right]_{\mathrm{i}}$ responses, represented by the changes in 340/380 ratio, to type 1 collagen at concentrations of 0.01 (low), 0.08 (medium), and 0.4 (high) $\mathrm{mg} / \mathrm{ml}$. C and $\mathbf{D}$ are the representative tracings from one experiment of high concentration collagen stimulation using ciliated and deciliated VSMCs, respectively.

of VSMCs. These perturbations give rise to dynamic intramural variations in stress/tension (force) and strain (deformation), transmitted to VSMCs via ECM. The composition, quantity and topography of ECM components also influence the magnitude of such perturbations. VSMCs are capable of sensing both the mechanical perturbations as well as the chemical properties of their surrounding ECM and respond accordingly by regulating the cellular contractile machinery and production/ organization of ECM [48]. Thus, VSMCs, by modifying the vessel walls functionally and structurally, allow the arteries to accommodate a wide range of perturbations. VSMCs are also shown to sense and respond to vascular injuries via integrin-mediated VSMC-ECM integration [49]. Although the physiological significance of such sensing/responding functions of VSMCs is well recog- nized, precisely in which subcellular site these mechanochemical signals are communicated remains undefined.

In this study, one striking observation consistent in all aortic sections examined is that primary cilia in the media layer not only extend deeply into ECM (fig. 2A-E), similar to those of connective tissue cells $[28,39]$, but also align with their long axis positioned at a specific angle, approximately $60^{\circ}$, in relation to the cross-sectional plane of the arteries (fig. 1B-D). This non-random orientation implies functional significance. Given that VSMCs are responsible for producing and laying down ECM, and conversely ECM exerts an important role in VSMC adhesion, migration, proliferation and differentiation [35], the unique position of VSMC primary cilia makes them ideal for sensing and relaying signals. How- 


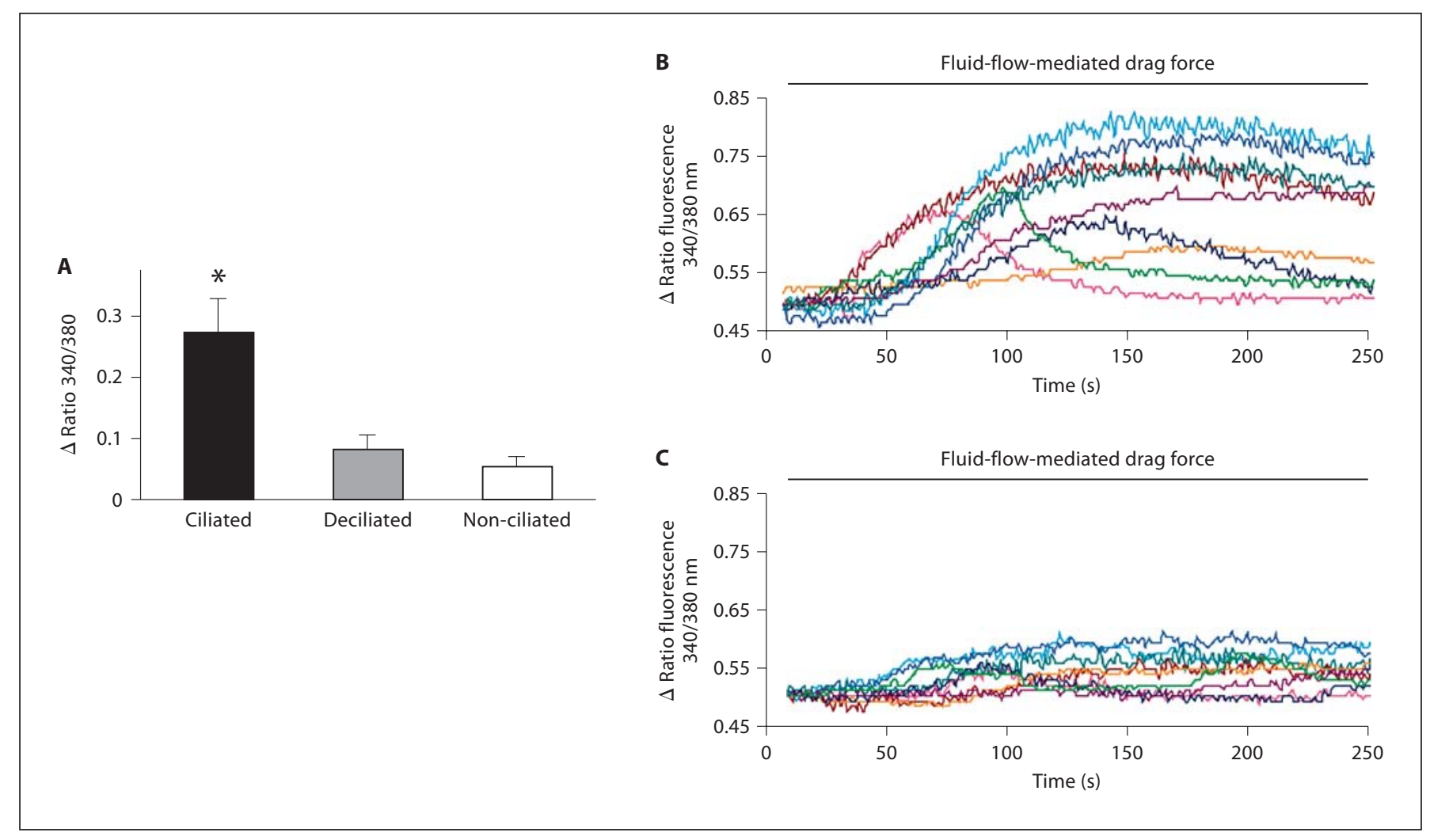

Fig. 7. A $\left[\mathrm{Ca}^{2+}\right]_{\mathrm{i}}$ responses, represented by the changes in ratio of $340 / 380$, to bending by a drag force induced by laminar fluid flow $\left(3.5 \mathrm{ml} \mathrm{min}^{-1}\right)$ in ciliated $0.273 \pm 0.03(\mathrm{n}=42)$, chloral hydrate deciliated $0.087 \pm 0.01$ $(\mathrm{n}=54)$, and non-ciliated (non-confluent) $0.066 \pm 0.009(\mathrm{n}=50)$ VSMCs, with 3 separate sets of experiments for each cell group $(\mathrm{p}<0.001)$ between ciliated vs. deciliated or non-ciliated VSMCs. ${ }^{*}$ Denotes a significant difference. $\mathbf{B}$ and $\mathbf{C}$ are the representative tracings from a single experiment using ciliated and deciliated VSMCs, respectively.

ever, exactly why primary cilia of VSMCs adopt an angled alignment is unclear. Intuitively, such alignment might allow cilia to discriminate directional stress/stain signals within an intact vessel wall in addition to an already greatly extended area of contact with the extracellular milieu, thereby further enhancing or fine-tuning the ability to transduce mechanochemical information bidirectionally.

The majority of ECM proteins in the vessel wall, such as collagen, laminin and fibronectin, contain matricryptic sites. After vessel injury, these normally hidden sites are exposed and interact with their receptors, the integrin family of proteins $[42,43]$. Integrins are membranelocated receptors important for detecting and responding to vascular injury via interacting to their ligands. The interaction of ECM-integrins induces multiple signal transduction events that modulate cell behavior $[45,46]$. The presence of $\alpha 3$ - and $\beta 1$-integrins in primary cilia of
VSMCs (fig. 3B), as also observed in cilia of MDCK cells and articular chondrocytes $[9,32]$, raises the possibility that primary cilia, through interacting with ECM protein, exert a role after vessel injury.

This possibility was tested in cultured VSMCs by both scratch-wounding experiments and direct stimulation with collagen. As shown in figure $4 \mathrm{~A}-\mathrm{C}$, while randomly distributed in the non-wounding areas, the majority of cilia of VSMCs at the wound edge were positioned towards the wound and ahead of the nuclei. This finding implies an interaction between matricryptic sites of ECM proteins (exposed by wounding) and ciliary integrins. This possibility was supported by the further demonstration that function-blocking anti- $\beta 1$-integrin antibody could significantly reduce the ciliary alignment after wounding (fig. 4D). The cellular response to ECM protein stimulation was also demonstrated by direct stimulation of VSMCs with type 1 collagen, one of the cognate 
ligands for $\alpha 3 \beta 1$-integrins. As shown in figure 6 , cilia significantly augmented VSMCs $\left[\mathrm{Ca}^{2+}\right]_{\mathrm{i}}$ response to collagen stimulation, indicating that primary cilia of VSMCs interact with ECM proteins via cilium-located integrins and transduce extracellular signals via modulation of $\left[\mathrm{Ca}^{2+}\right]_{\mathrm{i}}$. In vitro assays have shown that the leucine-rich repeats of $\mathrm{PC} 1$ also bind ECM proteins, and such binding induces an accelerated cellular proliferation [50]. In the current study, however, we limited our analysis to the immediate $\left[\mathrm{Ca}^{2+}\right]_{\mathrm{i}}$ response. We found that, despite the presence of endogenous $\mathrm{PC} 1$, this $\left[\mathrm{Ca}^{2+}\right]_{\mathrm{i}}$ response could be largely inhibited by a specific integrin blocker, akin to what has been observed in MDCK cells [9].

The orientation of primary cilia has long been implicated in determining the direction of cell migration in certain cellular systems. For example, primary cilia have been found to align in the direction of cell migration in $3 \mathrm{~T} 3$ cells $[40,51]$ and in rat $3 \mathrm{YI}$ cells during wound healing [41]. Consistent with these observations, we found that the deciliation resulted in a less efficient VSMC migration and wound filling (fig. 5). This observation, combined with the finding that cilia of VSMCs tended to preferentially position at the leading edge of the wound, provides further support to the notion that primary cilia exert a role in targeted cell migration. Taken together, our observations extended the previous reports and provide evidence indicating that primary cilia of VSMCs play a role in ECM sensing and directing migration via, at least in part, ciliary integrin-ECM interaction.

The majority of primary cilia in the aortic media exhibit varying degrees of deflection/bending (fig. 2). Bending of cilia is now recognized as the ciliary response to mechanical force within ECM $[39,52,53]$; the degree of deflection correlates with the intensity of force transmitted to the cilia [53]. Ciliary deflection in renal epithelial cells, by either direct manipulation [47] or fluid-flow-mediated force, activates intracellular $\mathrm{Ca}^{2+}$ signaling by triggering a transient $\left[\mathrm{Ca}^{2+}\right]_{i}$ rise, which is putatively initiated through ciliary PC2-mediated $\mathrm{Ca}^{2+}$ influx $[8,17]$. The $\left[\mathrm{Ca}^{2+}\right]_{\mathrm{i}}$ rise is therefore considered a readout for ciliummediated sensing. The observations of varying degrees of in situ ciliary deflection in the aortic media and the $\left[\mathrm{Ca}^{2+}\right]_{\mathrm{i}}$ response to a drag-force-induced ciliary deflection (fig. 7) strongly suggest that ciliary deflection in situ may represent mechanosensing of ECM tension, a role for cilia of VSMCs in vascular mechanosensing.

Primary cilia-mediated sensing in articular chondrocytes and osteoblast/osteoclasts exert roles in limb and skeletal development. Deficiency in such function results in manifestations including polydactyly, brachydactyly, skull deformity and abnormal ossification, and ectopic cartilage formation [31, 54-56]. The observations from the current study suggest the possibility that vascular leak and focal hemorrhages, manifested in $\mathrm{Pkd1}^{-/-}$and $P k d 2^{-/-}$mouse embryos, might be examples of vascular consequences resulting from an absence in polycystininvolved ciliary sensing in VSMCs. Whether Pkd mutation affects ciliary intergrin-ECM interaction is currently unknown. Further study of primary cilium-mediated functions in $P k d$ mutant vessels and VSMCs may illuminate this issue.

In summary, our present study demonstrates that primary cilia of VSMCs possess mechanical and ECM-sensing properties and likely represent one of the specific sensory sites in vasculature. Because pressure sensing and coordinated signaling between VSMCs and ECM are critical in regulating vascular tissue homeostasis, differentiation, growth, and injury repair [57-60], these cilium-mediated functions could potentially be important in the maintenance of vascular structural and functional integrity.

\section{Acknowledgements}

NIH DK63064 (Q.Q.), DK DK073567 (Q.Q.), HL74306 (G. C.S.), and FUTR Mayo Foundation (Q.Q.).

\section{References}

Satir P, Christensen ST: Overview of structure and function of mammalian cilia. Annu Rev Physiol 2007;69:377-400.

2 Wheatley DN, Wang AM, Strugnell GE: Expression of primary cilia in mammalian cells. Cell Biol Int 1996;20:73-81.

3 Gherman A, Davis EE, Katsanis N: The ciliary proteome database: an integrated community resource for the genetic and functional dissection of cilia. Nat Genet 2006;38: 961-962.

\footnotetext{
4 Pazour GJ: Comparative genomics: prediction of the ciliary and basal body proteome. Curr Biol 2004;14:R575-R577.

5 Pazour GJ, Agrin N, Leszyk J, Witman GB: Proteomic analysis of a eukaryotic cilium. J Cell Biol 2005;170:103-113.

6 Michaud EJ, Yoder BK: The primary cilium in cell signaling and cancer. Cancer Res 2006;66:6463-6467.
} 
7 Masyuk AI, Masyuk TV, Splinter PL, Huang BQ, Stroope AJ, LaRusso NF: Cholangiocyte cilia detect changes in luminal fluid flow and transmit them into intracellular $\mathrm{Ca}^{2+}$ and camp signaling. Gastroenterology 2006;131: 911-920.

$\checkmark 8$ Praetorius HA, Frokiaer J, Nielsen S, Spring KR: Bending the primary cilium opens $\mathrm{Ca}^{2+}$ sensitive intermediate-conductance $\mathrm{K}+$ channels in MDCK cells. J Membr Biol 2003; 191:193-200.

-9 Praetorius HA, Praetorius J, Nielsen S, Frokiaer J, Spring KR: Betal-integrins in the primary cilium of MDCK cells potentiate fibronectin-induced $\mathrm{Ca}^{2+}$ signaling. Am J Physiol Renal Physiol 2004;287:F969-F978.

10 Eggenschwiler JT, Anderson KV: Cilia and developmental signaling. Annu Rev Cell Dev Biol 2007;23:345-373.

11 Brueckner M: Heterotaxia, congenital heart disease, and primary ciliary dyskinesia. Circulation 2007;115:2793-2795.

-12 Badano JL, Mitsuma N, Beales PL, Katsanis $\mathrm{N}$ : The ciliopathies: An emerging class of human genetic disorders. Annu Rev Genomics Hum Genet 2006; 7:125-148

13 Mochizuki T, Wu G, Hayashi T, Xenophontos SL, Veldhuisen B, Saris JJ, Reynolds DM, Cai Y, Gabow PA, Pierides A, Kimberling WJ, Breuning MH, Deltas CC, Peters DJ, Somlo S: $P k d 2$, a gene for polycystic kidney disease that encodes an integral membrane protein. Science 1996;272:1339-1342.

-14 Delmas P: Polycystins: polymodal receptor/ ion-channel cellular sensors. Pflügers Arch 2005;451:264-276.

15 Clapham DE: Trp channels as cellular sensors. Nature 2003;426:517-524.

16 Li Q, Montalbetti N, Wu Y, Ramos A, Raychowdhury MK, Chen XZ, Cantiello HF: Polycystin-2 cation channel function is under the control of microtubular structures in primary cilia of renal epithelial cells. J Biol Chem 2006;281:37566-37575.

17 Nauli SM, Alenghat FJ, Luo Y, Williams E, Vassilev P, Li X, Elia AE, Lu W, Brown EM, Quinn SJ, Ingber DE, Zhou J: Polycystins 1 and 2 mediate mechanosensation in the primary cilium of kidney cells. Nat Genet 2003; 33:129-137.

$\checkmark 18$ Chapman AB, Rubinstein D, Hughes R, Stears JC, Earnest MP, Johnson AM, Gabow PA, Kaehny WD: Intracranial aneurysms in autosomal dominant polycystic kidney disease. N Engl J Med 1992;327:916-920.

19 Gabow PA, Ikle DW, Holmes JH: Polycystic kidney disease: prospective analysis of nonazotemic patients and family members. Ann Intern Med 1984;101:238-247.

20 Schacht F: Hypertension and Vascular Studies in Congenital Polycystic Kidney; thesis, University of Minnesota, 1930.

21 Qian Q, Younge BR, Torres VE: Retinal arterial and venous occlusions in patients with ADPKD. Nephrol Dial Transplant 2007;22: 1769-1771.
22 Qian Q, Hunter LW, Li M, Marin-Padilla M, Prakash YS, Somlo S, Harris PC, Torres VE, Sieck GC: Pkd2 haploinsufficiency alters intracellular calcium regulation in vascular smooth muscle cells. Hum Mol Genet 2003 12:1875-1880.

23 Qian Q, Hunter LW, Du H, Ren Q, Han Y, Sieck GC: Pkd2 ${ }^{+/-}$vascular smooth muscles develop exaggerated vasocontraction in response to phenylephrine stimulation. J Am Soc Nephrol 2007;18:485-493.

24 Kip SN, Hunter LW, Ren Q, Harris PC, Somlo S, Torres VE, Sieck GC, Qian Q: $\left[\mathrm{Ca}^{2+}\right]_{\mathrm{i}}$ reduction increases cellular proliferation and apoptosis in vascular smooth muscle cells: relevance to the ADPKD phenotype. Circ Res 2005;96:873-880.

25 Zimmerman KW: Beiträge zur Kenntnis einiger Drüsen und Epithelien. Arch Mikrosk Anat Entwicklungsmech 1898;52:552-706.

26 Poole CA, Jensen CG, Snyder JA, Gray CG, Hermanutz VL, Wheatley DN: Confocal analysis of primary cilia structure and colocalization with the Golgi apparatus in chondrocytes and aortic smooth muscle cells. Cell Biol Int 1997;21:483-494.

27 Praetorius HA, Spring KR: Removal of the MDCK cell primary cilium abolishes flow sensing. J Membr Biol 2003;191:69-76.

28 Poole CA, Zhang ZJ, Ross JM: The differential distribution of acetylated and detyrosinated $\alpha$-tubulin in the microtubular cytoskeleton and primary cilia of hyaline cartilage chondrocytes. J Anat 2001;199: 393-405.

29 Sheppard CJR, Cogswell CJ: Effects of aberrating layers and true length on confocal imaging properties. Optik 1991;87:34-38.

30 Jacobsen H, Hell SW: Effect of the specimen refractive index on the imaging of a confocal fluorescence microscope employing high aperture oil immersion lenses. Bioimaging 1995;3:39-47.

31 Xiao Z, Zhang S, Mahlios J, Zhou G, Magenheimer BS, Guo D, Dallas SL, Maser R, Calvet JP, Bonewald L, Quarles LD: Cilia-like structures and polycystin-1 in osteoblasts/ osteocytes and associated abnormalities in skeletogenesis and runx2 expression. J Biol Chem 2006;281:30884-30895.

32 McGlashan SR, Jensen CG, Poole CA: Localization of extracellular matrix receptors on the chondrocyte primary cilium. J Histochem Cytochem 2006;54:1005-1014.

33 Qian Q, Li M, Cai Y, Ward CJ, Somlo S, Harris PC, Torres VE: Analysis of the polycystins in aortic vascular smooth muscle cells. J Am Soc Nephrol 2003;14:2280-2287.

34 Damsky CH, Werb Z: Signal transduction by integrin receptors for extracellular matrix cooperative processing of extracellular information. Curr Opin Cell Biol 1992;4:772781 .
35 Carey DJ: Control of growth and differentiation of vascular cells by extracellular matrix proteins. Annu Rev Physiol 1991;53:161177.

36 Fassler R, Meyer M: Consequences of lack of $\beta 1$-integrin gene expression in mice. Genes Dev 1995;9:1896-1908.

>37 Kreidberg JA, Donovan MJ, Goldstein SL, Rennke H, Shepherd K, Jones RC, Jaenisch R: $\alpha 3 \beta 1$ integrin has a crucial role in kidney and lung organogenesis. Development 1996; 122:3537-3547.

38 Skinner MP, Raines EW, Ross R: Dynamic expression of $\alpha 1 \beta 1$ and $\alpha 2 \beta 1$ integrin receptors by human vascular smooth muscle cells. $\alpha 2 \beta 1$ integrin is required for chemotaxis across type I collagen-coated membranes. Am J Pathol 1994;145:1070-1081.

39 Jensen CG, Poole CA, McGlashan SR, Marko M, Issa ZI, Vujcich KV, Bowser SS: Ultrastructural, tomographic and confocal imaging of the chondrocyte primary cilium in situ. Cell Biol Int 2004;28:101-110.

40 Albrecht-Buehler G, Bushnell A: The orientation of centrioles in migrating 3T3 cells. Exp Cell Res 1979;120:111-118.

41 Katsumoto T, Higaki K, Ohno K, Onodera K: The orientation of primary cilia during the wound response in 3 Y1 cells. Biol Cell 1994; 81:17-21.

42 Hynes RO: Integrins: bidirectional, allosteric signaling machines. Cell 2002;110:673687.

43 Martinez-Lemus LA, Wu X, Wilson E, Hill MA, Davis GE, Davis MJ, Meininger GA: Integrins as unique receptors for vascular control. J Vasc Res 2003;40:211-233.

-44 Resnick A, Hopfer U: Force-response considerations in ciliary mechanosensation. Biophys J 2007;93:1380-1390.

45 Hynes RO: Integrins: versatility, modulation, and signaling in cell adhesion. Cell 1992;69:11-25

46 Hynes RO: A reevaluation of integrins as regulators of angiogenesis. Nat Med 2002;8: 918-921.

47 Praetorius HA, Spring KR: Bending the MDCK cell primary cilium increases intracellular calcium. J Membr Biol 2001;184:7179.

48 Gupta V, Grande-Allen KJ: Effects of static and cyclic loading in regulating extracellular matrix synthesis by cardiovascular cells. Cardiovasc Res 2006;72:375-383.

49 Newby AC: Matrix metalloproteinases regulate migration, proliferation, and death of vascular smooth muscle cells by degrading matrix and non-matrix substrates. Cardiovasc Res 2006;69:614-624.

50 Malhas AN, Abuknesha RA, Price RG: Interaction of the leucine-rich repeats of polycystin-1 with extracellular matrix proteins: possible role in cell proliferation. J Am Soc Nephrol 2002;13:19-26. 
-51 Albrecht-Buehler G: Phagokinetic tracks of 3T3 cells: Parallels between the orientation of track segments and of cellular structures which contain actin or tubulin. Cell 1977;12: 333-339.

52 Gallagher BC: Primary cilia of the corneal endothelium. Am J Anat 1980;159:475-484.

53 Poole CA, Flint MH, Beaumont BW: Analysis of the morphology and function of primary cilia in connective tissues: a cellular cybernetic probe? Cell Motil 1985;5:175193.
54 McGlashan SR, Haycraft CJ, Jensen CG, Yoder BK, Poole CA: Articular cartilage and growth plate defects are associated with chondrocyte cytoskeletal abnormalities in Tg737orpk mice lacking the primary cilia protein polaris. Matrix Biol 2007;26:234246.

55 Koyama E, Young B, Nagayama M, Shibukawa Y, Enomoto-Iwamoto M, Iwamoto M, Maeda Y, Lanske B, Song B, Serra R, Pacifici M: Conditional Kif3a ablation causes abnormal hedgehog signaling topography, growth plate dysfunction, and excessive bone and cartilage formation during mouse skeletogenesis. Development 2007;134:2159-2169.

-56 Haycraft CJ, Zhang Q, Song B, Jackson WS, Detloff PJ, Serra R, Yoder BK: Intraflagellar transport is essential for endochondral bone formation. Development 2007;134:307316.
57 Clowes AW, Schwartz SM: Significance of quiescent smooth muscle migration in the injured rat carotid artery. Circ Res 1985;56: 139-145.

58 Fingerle J, Johnson R, Clowes AW, Majesky MW, Reidy MA: Role of platelets in smooth muscle cell proliferation and migration after vascular injury in rat carotid artery. Proc Natl Acad Sci USA 1989;86:8412-8416.

59 Ross R: Cellular and molecular studies of atherogenesis. Atherosclerosis 1997; 131(suppl):S3-S4.

60 Raines EW: The extracellular matrix can regulate vascular cell migration, proliferation, and survival: relationships to vascular disease. Int J Exp Pathol 2000;81:173-182. 